JURNAL KEBIDANAN

Vol 7, No 1, Januari $2021: 46-50$

\title{
HUBUNGAN POLA AKTIFITAS DILUAR RUANGAN DENGAN TEKANAN DARAH PADA IBU HAMIL
}

\author{
Rizka Nur Fadilah¹, Dessy Hermawan², Yulistiana Evayanti ${ }^{3}$, Devi Kurniasari ${ }^{4}$ \\ 1,2,3,4Program Studi DIV Kebidanan Fakultas Kedokteran Universitas Malahayati Bandar Lampung \\ 1email: rizkanf26@gmail.com \\ 2email: hermawan.dessy@gmail.com \\ ${ }^{3}$ email: yulistianaevayanti@gmail.com \\ ${ }^{4}$ email: devikurniasari82@gmail.com
}

\section{ABSTRACT RELATIONSHIP PATTERN BEYOND ITS ACTIVITY ROOM WITH A BLOOD PRESSURE IN PREGNANT WOMEN}

Background: Indonesia is a tropical area with sun exposure occurs throughout the year, but the Indonesian population is still at risk for vitamin D. This happens because one of them is female using a closed clothes are still many activities carried out in an enclosed space that does not get direct sunlight exposure, Another thing that affects vitamin $D$ deficiency that women who use clothes covered and rarely exposed to sunlight, as well as women who always use sunscreen also contribute to prevent the entry of ultraviolet rays from the sun to the skin, so that reduced synthesis of vitamin $D$ in the skin as well as a lack of vitamin $D$. as a result, the risk of degenerative diseases such as hypertension.

Purpose from research to determine the relationship between outdoor activity patterns and blood pressure in pregnant women at PMB Fitri Hayati, SST Bandar Lampung in 2019.

Method: The study design using analytic correlation using primary data. Conducted from June to August with the sample in the study were as many as 30 respondents. Research by the sampling technique is random sampling. Collecting data using questionnaires and statistical data analysis using chi square test.

result: From the results of research conducted by the authors that note of 6 respondents were active in the building as much as 4 respondents (66.7\%) blood pressure is not normal and 2 respondents (33.3\%) normal blood pressure. While 24 respondents were active outside the building as much as 3 respondents (12.5\%) abnormal blood pressure and 21 respondents (87.5\%) normal blood pressure. The results of chi-square statistic test obtained with $p$-value $=0.005<\alpha(0.05)$. With the obtained value is a systolic blood pressure of 100-130 and diastolic 70-80 $\mathrm{mmHg}$.

Conclusion: There is a pattern of activity outdoors relationship with blood pressure in pregnant women in PMB FitriHayati, SST Bandar Lampung 2019.

Suggestion It is hoped that this research can be applied by the respondents to be one of the solutions in order to stabilize blood pressure or prevent hypertension or anemia. This can be done at least every 3 times a week from 07.00 - 09.00 for a minimum time between 15-30 minutes. This can be done for those who are wearing hijab, if they leave the house wearing long clothes, it is recommended that when inside the house they are wearing short clothes, exposure to the sun can be from the window glass or behind the house that is beaged but there can still be light entering the house and avoid wearing sunblock in the morning. can block the content on exposure to direct sunlight.

Keywords : The pattern of activity outdoors, Blood Pressure, Vitamin D

\section{ABSTRAK}

Latar Belakang: Indonesia merupakan daerah tropis dengan paparan sinar matahari terjadi sepanjang tahun, tetapi penduduk Indonesia masih berisiko mengalami kekurangan vitamin D. Hal ini terjadi karena salah satunya yaitu perempuan menggunakan pakaian tertutup yang masih banyak kegiatan yang dilakukan di dalam ruang tertutup yang tidak mendapatkan paparan sinar matahari langsung. Hal lain yang mempengaruhi kekurangan vitamin $\mathrm{D}$ yaitu perempuan yang menggunakan pakaian tertutup dan jarang terpapar sinar matahari, serta perempuan yang selalu menggunakan tabir surya juga berperan menghambat masuknya sinar ultraviolet dari sinar matahari ke kulit, sehingga berkurang sintesa vitamin $D$ di kulit serta kurangnya konsumsi vitamin $D$. Akibatnya berisiko terjadinya penyakit degeneratif seperti hipertensi. 
Tujuan dari penelitian Untuk mengetahui hubungan pola aktifitas diluar ruangan dengan Tekanan Darah pada ibu hamil di PMB Fitri Hayati, SST Bandar Lampung Tahun 2019.

Metode :Desain penelitian menggunakan analitik dengan pendekatan korelasi menggunakan data primer. Dilakukan dari bulan Juni sampai dengan Agustus dengan sampel dalam penelitian adalah sebanyak 30 orang responden. Penelitian dengan teknik sampling yaitu random sampling. Pengumpulan data menggunakan kuisioner dan analisa data menggunakan uji statistic chi square.

Hasil: Dari hasil penelitian yang dilakukan oleh penulis bahwa diketahuidari 6 responden yang aktif di dalam gedung sebanyak 4 responden $(66,7 \%)$ Tekanan darah tidak normal dan 2 responden $(33,3 \%)$ Tekanan darah normal. Sedangkan dari 24 responden yang aktif diluar gedung sebanyak 3 responden $(12,5 \%)$ tekanan darah tidak normal dan 21 responden (87,5\%) Tekanan darah normal. Hasil uji statistic chi-square diperoleh dengan nilai $p$-value $=0,005<\alpha(0,05)$. Dengan didapat nilai tekanan darah yaitu sistolik $100-130$ dan diastolic $70-80 \mathrm{mmHg}$.

Kesimpulan: Ada hubungan pola aktifitas diluar ruangan dengan tekanan darah pada ibu hamil di PMB FitriHayati, SST Bandar Lampung Tahun 2019.

Saran Diharapkan dengan adanya penelitian ini dapat diaplikasikan oleh para responden untuk dijadikan salah satu solusi agar dapat menstabilkan tekanan darah ataupun mencegah terjadinya hipertensi maupun anemia. Ini bisa dilakukan minimal setiap seminggu 3 kali dari pukul $07.00-09.00$ dalam waktu minimal antara $15-30$ menit. Ini bisa dilakukan bagi yang berhijab jika keluar rumah memakai pakaian panjang disarankan ketika didalam rumah sedang memakai pakaian pendek melakukan paparan sinar matahari bisa dari kaca jendela ataupun belakang rumah yang dipager namun masih bisa ada cahaya yang masuk kedalam rumah dan hindari memakai sunblock pada pagi hari yang dapat menghalangi kandungan pada paparan sinar matahari langsung.

Kata Kunci: PolaAktifitasdiluarruangan, TekananDarah, Vitamin D

\section{PENDAHULUAN}

Indonesia merupakan daerah tropis dengan paparan sinar matahari terjadi sepanjang tahun, tetapi penduduk Indonesia masih berisiko mengalami kekurangan vitamin $\mathrm{D}$. Hal ini terjadi karena salah satunya yaitu perempuan menggunakan pakaian tertutup yang masih banyak kegiatan yang dilakukan di dalam ruang tertutup yang tidak mendapatkan paparan sinar matahari langsung. Hal lain yang mempengaruhi kekurangan vitamin $D$ yaitu perempuan yang menggunakan pakaian tertutup dan jarang terpapar sinar matahari, serta perempuan yang selalu menggunakan tabir surya juga berperan menghambat masuknya sinar ultraviolet dari sinar matahari ke kulit, sehingga berkurang sintesa vitamin $D$ di kulit serta kurangnya konsumsi vitamin D. Akibatnya berisiko terjadinya penyakit degeneratif seperti hipertensi (Masulili, 2017).

Faktor yang berkontribusi terhadap penyebab kematian ibu secara garis besarnya dapat dikelompokkan menjadi penyebab langsung dan penyebab tidak langsung. Penyebab langsung kematian ibu salah satunya adalah preeklamsi/eklamsi. Preeklamsia adalah gangguan kehamilan yang serius yang memengaruhi hingga $8 \%$ dari kehamilan di seluruh dunia. Prevalensi dapat berkisar antara $10 \%$ sampai $18 \%$ di beberapa negara berkembang.Preeklamsi merupakan gangguan multifaktorial yang terjadi sebagai suatu akumulasi dari faktor-faktor yang mungkin melibatkan faktor maternal, faktor plasenta dan faktor janin. Kejadian preeklamsi tidak hanya menimbulkan dampak bagi kesehatan ibu hamilsaja tapi juga mempunyai dampak bagi pertumbuhan dan perkembangan janin.Komplikasi yang di timbulkan dapat berupa keadaan akut maupun kronis. Banyak teori yang dianut tentang penyebab preeklamsi antara lain: teori kelainan vaskularisasi plasenta, teori iskemia plasenta, radikal bebas, dan disfungsi endotel, teori imunologik, teori genetik, teori defisiensi gizi, dan teori inflamasi. Walaupun demikian yang menjadi dasar pencetus untuk patogenesis dari preeklamsi adalah kerusakan yang berhubungan dengan plasenta. Hampir semua ahli sepakat bahwa vasospasme merupakan awal preeklamsi.

Pola aktifitas diluar ruangan dengan paparan sinar matahari yang berperan sebagai vitamin $D$ menunjukkan bahwa vitamin $D$ juga memiliki sasaran kerja dibagian sebelum CAMP, yaitu dengan menekan ekspresi COX-2 di sel macula densa ginjal. Hal ini terlihat bahwa tidak adanya peningkatan kadar rennin darah, walaupun hewan uji coba telah diberi teofilin (bahan untuk menciptakan akumulasi cAMP), hal ini terjadi karena vitamin D telah menekan ekspresi COX-2 di bagian atas cAMP, sehingga dari dua mekanisme kerja vitamin $D$ dalam proses pengaturan tekanan darah, yaitu dengan cara menghambat transkripsi gen rennin dan menghambat ekspresi COX-2 di sel macula densa. Kekurangan vitamin $\mathrm{D}$ dalam darah, tidak hanya 
akan meningkatkan tekanan darah sistolik dan diastolic, tapi juga terjadinya arterioklerosis .

Penelitian Stephen G. Rostand (2017) menjelaskan kenaikan tekanan darah yang dicatat pada individu yang tinggal semakin meningkatkan jarak dari khatulistiwa. Apalagi dalam sebuah penelitian kecil, subyek yang terpapar radiasi UVB seluruh tubuh tidak hanya memiliki penurunan tekanan darah tetapi juga peningkatan simultan pada $25(\mathrm{OH}) \mathrm{D}$. Bersama dengan temuan ini kekurangan vitamin D/ ketidakcukupan dapat menyebabkan perbedaan ras, musiman, dan geografis dalam tekanan darah dan dengan demikian dapat memainkan peran secara langsung atau tidak langsung dalam pathogenesis dan pemeliharaan hipertensi dan penyakit kardiovaskular.

Berdasarkan hasil presurvey yang telah dilakukan di PMB Fitri Hayati, SST Bandar Lampung didapatkan ibu hamil yang melakukan ANC dari bulan Januari - Mei Tahun 2019 sebanyak 411 ibu hamil. Dari data yang didapatkan ditemukan paling banyak tekanan darah normal dan diketahui ibu-ibu hamil sering melakukan pola aktifitas diluar ruangan seperti mencuci, menjemur pakaian, mengantar anak sekolah pagi hari dll.

Diketahui hubungan pola aktifitas diluar ruangan dengan Tekanan Darah pada ibu hamil di PMB Fitri Hayati, SST Bandar Lampung Tahun 2019.

\section{METODOLOGI PENELITIAN}

Penelitian ini dilakukan di PMB Fitri Hayati, SST di Jl. Imam Bonjol, Jl. Salak no. 10, Gedong Air Kec. Tj. Karang Barat, Kota Bandar Lampung. Waktu Penelitian ini dilaksanakan pada bulan Juni Agustus 2019. Dalam penelitian ini menggunakan analitik dengan menggunakan pendekatan Korelasi. Ciri dari desain penelitian ini melihat atau menilai seberapa normal tekanan darah pada ibu hamil dengan paparan sinar matahari.Peneliti melakukan wawancara langsung terhadap ibu hamil serta melakukan pengukuran tekanan darah dan menanyakan bagaimana pola aktifitas ibu diluar ruangan dan dalam ruangan. Sampel dalam penelitian ini adalah Ibu hamil TM I - III dengan pengukuran tekanan darah dan teknik sampling yang digunakan dalam penelitian ini adalah Random sampling.

\section{HASIL PENELITIAN}

Analisa Univariat

Distribusi Frekuensi Pola Aktifitas Pada Ibu Hamil

Berdasarkan table 1 dibawah dapat disimpulkan bahwa dari 30 responden ibu hamil yang melakukan aktifitas diluar gedung yaitu 24 responden $(80 \%)$ dan yang melakukan aktifitas didalam gedung yaitu 6 responden $(20 \%)$.

Tabel 1.

Distribusi Frekuensi Pola Aktifitas Pada lbu Hamil di PMB Fitri Hayati, SST Bandar Lampung Tahun 2019

\begin{tabular}{ccc}
\hline Aktifitas & Jumlah Responden & Persentase (\%) \\
\hline Aktif diluar gedung & 24 & $80 \%$ \\
Aktif didalam gedung & 6 & $20 \%$ \\
\hline Jumlah & 30 & $100 \%$ \\
\hline
\end{tabular}

Distribusi Frekuensi Tekanan Darah Pada Ibu Hamil

Berdasarkan table 2 dibawah dapat diketahui bahwa dari 30 responden ibu yang memiliki tekanan darah normal terdapat 23 responden $(76,7 \%)$ dan ibu yang memiliki tekanan darah tidak normal terdapat 7 responden $(23,3 \%)$.

Tabel 2.

Distribusi Frekuensi Tekanan Darah Pada Ibu Hamil di PMB Fitri Hayati, SST Bandar Lampung Tahun 2019

\begin{tabular}{|c|c|c|}
\hline Tekanan Darah & Jumlah Responden & Persentase (\%) \\
\hline Normal & 23 & $76,7 \%$ \\
\hline Tidak Normal & 7 & $23,3 \%$ \\
\hline Jumlah & 30 & $100 \%$ \\
\hline
\end{tabular}


sebanyak 4 responden $(66,7 \%)$ Tekanan darah tidak normal dan 2 responden $(33,3 \%)$ Tekanan darah normal. Sedangkan dari 24 responden yang aktif diluar gedung sebanyak 3 responden $(12,5 \%)$ tekanan darah tidak normal dan 21 responden $(87,5 \%)$ Tekanan darah normal. Hasil uji statistic chisquare diperoleh $p$-value $=0,005$ dimana nilai $P<\alpha$ $(0,05)$ yang berarti $\mathrm{Ha}$ diterima sehingga dapat disimpulkan bahwa ada hubungan pola aktifitas diluar ruangan dengan tekanan darah pada ibu hamil di PMB Fitri Hayati, SST Bandar Lampung Tahun 2019. Analisa antara hubungan kedua variabel ditunjukkan oleh OR yang didapat 14 (1,741 $112,551)$ yang artinya ibu hamil yang melakukan aktifitas didalam gedung mempunyai resiko 14 kali lebih besar untuk megalami Tekanan Darah tidak normal dibandingkan dengan ibu hamil yang melakukan aktifitas diluar gedung.

Tabel 3.

Hubungan Pola Aktifitas diluar Ruangan dengan Tekanan Darah Pada Ibu Hamil di PMB Fitri Hayati, SST Bandar Lampung Tahun 2019

\begin{tabular}{|c|c|c|c|c|c|c|c|c|}
\hline \multirow{3}{*}{ Pola Aktifitas } & \multicolumn{4}{|c|}{ Tekanan Darah } & \multicolumn{2}{|c|}{ Total } & \multirow{3}{*}{$\begin{array}{c}P \\
\text { Value }\end{array}$} & \multirow{3}{*}{ OR } \\
\hline & \multicolumn{2}{|c|}{ Tidak Normal } & \multicolumn{2}{|c|}{ Normal } & \multirow{2}{*}{ N } & \multirow{2}{*}{$\%$} & & \\
\hline & $\mathbf{N}$ & $\%$ & $\mathbf{N}$ & $\%$ & & & & \\
\hline Aktif didalam gedung & 4 & $66,7 \%$ & 2 & $33,3 \%$ & 6 & $100 \%$ & 0005 & 14 ( Cl 1,741 - \\
\hline Aktif diluar gedung & 3 & $12,5 \%$ & 21 & $87,5 \%$ & 24 & $100 \%$ & $0,00 J$ & 112,551) \\
\hline
\end{tabular}

\section{PEMBAHASAN}

Berdasarkan hasil penelitian ibu hamil yang melakukan aktifitas diluar gedung yaitu 24 responden $(80 \%)$ Pola aktifitas diluar ruangan dengan paparan sinar matahari yang berperan sebagai vitamin $D$ menunjukkan bahwa vitamin $D$ juga memiliki sasaran kerja dibagian sebelum cAMP, yaitu dengan menekan ekspresi COX-2 di sel macula densa ginjal. Hal ini terlihat bahwa tidak adanya peningkatan kadar rennin darah, walaupun hewan uji coba telah diberi teofilin (bahan untuk menciptakan akumulasi cAMP), hal ini terjadi karena vitamin $\mathrm{D}$ telah menekan ekspresi COX-2 di bagian atas CAMP, sehingga dari dua mekanisme kerja vitamin $D$ dalam proses pengaturan tekanan darah, yaitu dengan cara menghambat transkripsi gen rennin dan menghambat ekspresi COX-2 di sel macula densa. Kekurangan vitamin $\mathrm{D}$ dalam darah, tidak hanya akan meningkatkan tekanan darah sistolik dan diastolic, tapi juga terjadinya arterioklerosis. Dari 30 responden ibu yang memiliki tekanan darah normal terdapat 23 responden (76,7\%). Penelitian Stephen G. Rostand (2017) menjelaskan kenaikan tekanan darah yang dicatat pada individu yang tinggal semakin meningkatkan jarak dari khatulistiwa. Apalagi dalam sebuah penelitian kecil, subyek yang terpapar radiasi UVB seluruh tubuh tidak hanya memiliki penurunan tekanan darah tetapi juga peningkatan simultan pada $25(\mathrm{OH}) \mathrm{D}$. Bersama dengan temuan ini kekurangan vitamin D/ ketidakcukupan dapat menyebabkan perbedaan ras, musiman, dan geografis dalam tekanan darah dan dengan demikian dapat memainkan peran secara langsung atau tidak langsung dalam pathogenesis dan pemeliharaan hipertensi dan penyakit kardiovaskular.

Faktor yang berkontribusi terhadap penyebab kematian ibu secara garis besarnya dapat dikelompokkan menjadi penyebab langsung dan penyebab tidak langsung. Penyebab langsung kematian ibu salah satunya adalah preeklamsi/eklamsi. Preeklamsia adalah gangguan kehamilan yang serius yang memengaruhi hingga $8 \%$ dari kehamilan di seluruh dunia. Prevalensi dapat berkisar antara $10 \%$ sampai $18 \%$ di beberapa negara berkembang.Preeklamsi merupakan gangguan multifaktorial yang terjadi sebagai suatu akumulasi dari faktor-faktor yang mungkin melibatkan faktor maternal, faktor plasenta dan faktor janin. Kejadian preeklamsi tidak hanya menimbulkan dampak bagi kesehatan ibu hamilsaja tapi juga mempunyai dampak bagi pertumbuhan dan perkembangan janin.Komplikasi yang di timbulkan dapat berupa keadaan akut maupun kronis. Banyak teori yang dianut tentang penyebab preeklamsi antara lain: teori kelainan vaskularisasi plasenta, teori iskemia plasenta, radikal bebas, dan disfungsi endotel, teori imunologik, teori genetik, teori defisiensi gizi, dan teori inflamasi. Walaupun demikian yang menjadi dasar pencetus untuk patogenesis dari preeklamsi adalah kerusakan yang berhubungan dengan plasenta. Hampir semua ahli sepakat bahwa vasospasme merupakan awal preeklamsi.

\section{KESIMPULAN}

Berdasarkan hasil penelitian dan pembahasan hubungan pola aktifitas diluar ruangan dengan tekanan darah pada ibu hamil di PMB Fitri 
Hayati, SST Bandar Lampung Tahun 2019 yaitu Diketahui responden berdasarkan pola aktifitas diluar ruangan pada ibu hamil sebanyak 24 orang $(80 \%)$.Berdasarkan pola aktifitas dengan tekanan darah pada ibu hamil dari 6 responden yang aktif didalam gedung sebanyak 4 responden $(66,7 \%)$ Tekanan darah tidak normal dan 2 responden $(33,3 \%)$ Tekanan darah normal. Sedangkan dari 24 responden yang aktif diluar gedung sebanyak 3 responden (12,5\%) tekanan darah tidak normal dan 21 responden (87,5\%) Tekanan darah normal. Maka dari itu ada hubungan pola aktifitas diluar ruangan dengan tekanan darah pada ibu hamil ( $p$ value $<=$ $0,005)$. Dengan didapat nilai tekanan darah yaitu sistolik $100-130$ dan diastolic $70-80 \mathrm{mmHg}$.

\section{SARAN}

Diharapkan dengan adanya penelitian ini dapat diaplikasikan oleh para responden untuk dijadikan salah satu solusi agar dapat menstabilkan tekanan darah ataupun mencegah terjadinya hipertensi maupun anemia. Ini bisa dilakukan minimal setiap seminggu 3 kali dari pukul 07.00 09.00 dalam waktu minimal antara 15 - 30 menit. Ini bisa dilakukan bagi yang berhijab jika keluar rumah memakai pakaian panjang disarankan ketika didalam rumah sedang memakai pakaian pendek melakukan paparan sinar matahari bisa dari kaca jendela ataupun belakang rumah yang dipager namun masih bisa ada cahaya yang masuk kedalam rumah dan hindari memakai sunblock pada pagi hari yang dapat menghalangi kandungan pada paparan sinar matahari langsung.

\section{DAFTAR PUSTAKA}

Amelia, Sylvi Wafda Nur. 2019. Asuhan Kebidanan Kasus Kompleks Maternal \& Neonatal. Yogyakarta: Pustaka Baru Press.

Debora, Oda. 2011. Proses Keperawatan dan Pemeriksaan Fisik. Jakarta: Salemba Medika.

Dinkes Provinsi Lampung. 2016. Profil Kesehatan Lampung 2017. Lampung
Hermawan, Dessy. 2016. Sehat Selalu dengan Vitamin D. Yogyakarta: CV Andi Offset.

Johnson, Ruth. 2013. Keterampilan Dasar Praktik Klinik Kebidanan Edisi 3. Jakarta: EGC Medical Publisher

Kemenkes RI. 2017. Profil Kesehatan Indonesia 2017. Jakarta

Notoatmodjo, 2012. Metodologi Penelitian Kesehatan. Jakarta : Rineka Cipta

Rimahardika, Rosita. 2017. Asupan Vitamin D dan Paparan Sinar Matahari pada Orang yang Bekerja di Dalam Ruangan dan di Luar Ruangan. Skripsi Universitas Diponegoro, April.

Rostand, Stephen G. 2017. Associations of Blood Pressure, Sunlight, and Vitamin D in Community-Dwelling Adults: Reasons for Geographic and Racial Differences in Stroke (Regards) Study. HHS Public Access, September ; 34 (9): 1704-1710. Doi:101097/HJH.0000000000001018.

Rukiyah, Ai Yeyeh. 2010. Asuhan Kebidanan Patologi Kebidanan. Jakarta: CV. Trans Info Media

Rukiyah, Ai Yeyeh. 2013. Asuhan Kebidanan 1 Kehamilan. Jakarta: CV. Trans Info Media

Sakamoto, R. 2012. Relationship of Vitamin D levels to blood pressure in a biethnic population. $\mathrm{NIH}$ Public Access, August;23(8): 776-784. Doi: 10.1016/j.numecd.2021.04.014

Sugiyono. 2017. Statistika Untuk Penelitian, Bandung: Alfabeta.

Walyani, Elisabeth Siwi. 2015. Asuhan Kebidanan Kegawatdaruratan Maternal \& Neonatal. Yogyakarta: Pustaka Baru Press.

Walyani, Elisabeth Siwi. 2015. Asuhan Kebidanan Pada Kehamilan. Yogyakarta: Pustaka Baru Press.

WHO. 2017. Global Health Observatory (GHO) data Maternal Mortality. 